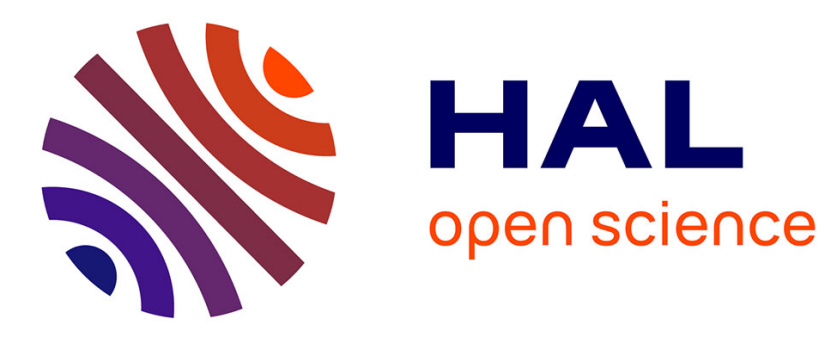

\title{
Temocillin susceptibility among Enterobacterales strains recovered from blood culture in France
}

Eric Farfour, Anne-Gaëlle Si Larbi, Vincent Cattoir, Stéphane Corvec, Thomas Guillard, Antoine Grillon, Christophe Isnard, Audrey Mérens, Nicolas Degand, Typhaine Billard-Pomares, et al.

\section{To cite this version:}

Eric Farfour, Anne-Gaëlle Si Larbi, Vincent Cattoir, Stéphane Corvec, Thomas Guillard, et al.. Temocillin susceptibility among Enterobacterales strains recovered from blood culture in France. Diagnostic Microbiology and Infectious Disease, 2021, 100 (3), pp.115368. 10.1016/j.diagmicrobio.2021.115368 . hal-03216705

\section{HAL Id: hal-03216705 \\ https://hal.univ-reims.fr/hal-03216705}

Submitted on 27 May 2021

HAL is a multi-disciplinary open access archive for the deposit and dissemination of scientific research documents, whether they are published or not. The documents may come from teaching and research institutions in France or abroad, or from public or private research centers.
L'archive ouverte pluridisciplinaire HAL, est destinée au dépôt et à la diffusion de documents scientifiques de niveau recherche, publiés ou non, émanant des établissements d'enseignement et de recherche français ou étrangers, des laboratoires publics ou privés. 


\section{Journal Pre-proof}

Temocillin susceptibility among Enterobacterales strains recovered from blood culture in France

Eric Farfour, Anne-Gaëlle Si Larbi, Vincent Cattoir , Stéphane Corvec, Thomas Guillard, Antoine Grillon , Christophe Isnard, Audrey Mérens, Nicolas Degand, Typhaine Billard-Pomares, Damien Fournier, Emmanuelle Bille, Cécile Le Brun, Chloé Plouzeau, Emilie Flevin , Nicolas Yin, Paul-Louis Woerther, Julie Lourtet, Philippe Lesprit, Alban Le Monnier, on behalf of the GMC study group

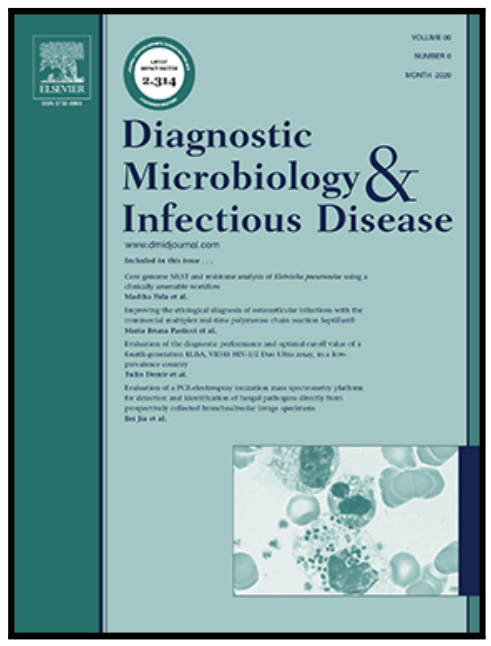

PII:

DOI: S0732-8893(21)00061-4

Reference: https://doi.org/10.1016/j.diagmicrobio.2021.115368

DMB 115368

To appear in: Diagnostic Microbiology \& Infectious Disease

Received date: $\quad 10$ November 2020

Accepted date: $\quad 5$ March 2021

Please cite this article as: Eric Farfour, Anne-Gaëlle Si Larbi, Vincent Cattoir, Stéphane Corvec , Thomas Guillard, Antoine Grillon, Christophe Isnard, Audrey Mérens, Nicolas Degand, Typhaine Billard-Pomares, Damien Fournier, Emmanuelle Bille, Cécile Le Brun, Chloé Plouzeau, Emilie Flevin, Nicolas Yin, Paul-Louis Woerther, Julie Lourtet, Philippe Lesprit, Alban Le Monnier, on behalf of the GMC study group, Temocillin susceptibility among Enterobacterales strains recovered from blood culture in France, Diagnostic Microbiology \& Infectious Disease (2021), doi: https://doi.org/10.1016/j.diagmicrobio.2021.115368

This is a PDF file of an article that has undergone enhancements after acceptance, such as the addition of a cover page and metadata, and formatting for readability, but it is not yet the definitive version of record. This version will undergo additional copyediting, typesetting and review before it is published in its final form, but we are providing this version to give early visibility of the article. Please note that, during the production process, errors may be discovered which could affect the content, and all legal disclaimers that apply to the journal pertain.

(C) 2021 Published by Elsevier Inc. 
Temocillin susceptibility among Enterobacterales strains recovered from blood culture in France

Eric Farfour ${ }^{a^{*}}$, Anne-Gaëlle Si Larbi ${ }^{a}$, Vincent Cattoir ${ }^{b, c}$, Stéphane Corvec ${ }^{d}$, Thomas Guillard ${ }^{\mathrm{e}, \mathrm{f}}$, Antoine Grillon $^{\mathrm{g}}$, Christophe Isnard ${ }^{\mathrm{h}}$, Audrey Mérens ${ }^{\mathrm{i}}$, Nicolas Degand ${ }^{\mathrm{j}}$, Typhaine Billard-Pomares ${ }^{\mathrm{k}}$, Damien Fournier', Emmanuelle Bille ${ }^{m, n}$, Cécile Le Brun ${ }^{\circ}$, Chloé Plouzeau ${ }^{p}$, Emilie Flevin ${ }^{q}$, Nicolas Yin ${ }^{r}$, PaulLouis Woerther ${ }^{\mathrm{s}}$, Julie Lourtet ${ }^{\mathrm{t}}$, Philippe Lesprit ${ }^{\mathrm{a}}$, Alban Le Monnier ${ }^{\mathrm{t}}$, on behalf of the GMC study group

a Department of clinical biology, Hôpital Foch, Suresnes, France;

${ }^{b}$ Department of microbiology and hygiene, CHU de Rennes, Rennes, France;

${ }^{c}$ National reference laboratory for antibiotic resistance in Enterococcus spp, Rennes, France;

${ }^{d}$ Department of microbiology and hygiene, CHU de Nantes, Nantes, France;

e Department of microbiology, $\mathrm{CHU}$ de Reims, Reims, France;

If Inserm UMR-S 1250, Reims, France;

$g$ Institut of Bactériology, Hôpitaux Universitaires de Strasbourg, Strasbourg, France;

${ }^{h}$ Normandie Univ, UNICAEN, CHU de Caen Normandie, Department of microbiology, 14000 Caen, France;

'Department of microbiology and hygiene, Hôpital d'Instruction des Armées Bégin, Saint-Mandé, France;

'Department of microbiology, CHU de Nice, Nice, France;

${ }^{k}$ Department of microbiology and hygiene, CHU Avicenne, Bobigny, France;

' Department of microbiology, CHRU de Besançon, Besançon, France;

${ }^{m}$ Department of microbiology, Hôpital Necker-Enfants Malades, APHP Paris, Paris, France;

${ }^{n}$ Institut Necker-Enfants Malades, Université Paris Descartes, INSERM U1151, CNRS UMR 8253, Paris, France;

${ }^{\circ}$ Department of microbiology, CHU Bretonneau, Tours, France;

${ }^{p}$ Department of microbiology and hygiene, CHU de Poitiers, Poitiers, France;

${ }^{a}$ Department of biology, Hôpital de Dieppe, Dieppe, France;

${ }^{r}$ Department of microbiology Institut Gustave Roussy, Université Paris-Saclay, Villejuif, France; ${ }^{s}$ Department of microbiology, CHU H. Mondor, Créteil, France;

${ }^{t}$ Department of microbiology, GH Paris - Saint-Joseph, Paris, France;

* Corresponding author. Department of clinical Biology, Hôpital Foch, 40 rue Worth, 92150 Suresnes, France, Tel. +336988561 64; e-mail:ericf6598@yahoo.fr ; e.farfour@hopital-foch.org

Running title: change in temocillin susceptibility among Enterobacterales

Keywords: Temocillin; Extended-spectrum beta-lactamases (ESBL); third-generation cephalosporin (3GC); Antibiotic resistance; cephalosporinase-overproducing strain (COPE)

Highlights

- Cephalosporinase-overproducer Enterobacterales are significantly more resistant to temocillin than ESBL-producing Enterobacterales (37.7\% vs $23.5 \%$; $P<0.01$ );

- The rate of temocillin resistance is correlated to the number of inactive beta-lactams, ranging from $3.7 \%$ to $60.0 \%$ in strain susceptible to all beta-lactams and those resistant to 3 betalactams;

- Among third-generation cephalosporin-resistant Enterobacterales, temocillin was active against $64.9 \%$ of the strains non-susceptible to piperacillin-tazobactam, ofloxacin, and cotrimoxazole. 
- In ESBL-producing strains, the rate of resistance to temocillin trend to increase from $13.9 \%$ in 2014 to $23.9 \%$ in $2017(P<0.01)$.

\begin{abstract}
Temocillin is used for several years in some European countries but, only since 2015 in France. We assessed the susceptibility of Enterobacterales strains isolated from blood culture one year before (2014) and two years after (2017) its use in France. 1,387 strains were included by 17 clinical laboratories located throughout France: 363 in 2014 and 1,024 in 2017. The rate of resistance to temocillin was $4.6 \%$ and $26.7 \%$ in $3^{\text {rd }}$ generation cephalosporin (3GC) susceptible and resistant strains respectively. Cephalosporinase-overproducer (COPE) strains were significantly more resistant to temocillin (37.7\%) than ESBL-producer (ESBL-PE) $(23.5 \%)(P<0.01)$. The rate of temocillin resistance was correlated to the number of inactive beta-lactams. The rate of resistance to temocillin trend to increase from $13.9 \%$ in 2014 to $23.9 \%$ in $2017(P<0.01)$. Temocillin remains highly active against Enterobacterales but the trend in resistance should be assessed over time.
\end{abstract}




\section{Introduction}

Temocillin is a 6-a-methoxy derivative of ticarcillin which has been synthesized in the early 1980's (Labia et al. 1984). The 6-a-methoxy group confers to the molecule intrinsic stability against most beta-lactamases such as penicillinase, extended-spectrum beta-lactamase (ESBL), AmpC, and KPC carbapenemase (Woodford et al. 2014). Temocillin has been introduced in Belgium and Luxembourg in the 1980s, and in the United Kingdom in 2006. In the context of the 1980s, characterized by the development and marketing of several new antibiotics and the low prevalence of antibiotic resistance, temocillin was not considered by the health authority and the medical community useful enough in France as in many other countries. However, the worldwide pandemic of ESBL-producing Enterobacterales (ESBL-PE) and then the emergence of carbapenemase-producing Enterobacterales have led to a renewed interest in this molecule. In European countries, the average rate of resistance to a third-generation cephalosporin (3GC) in 2018 was $15.1 \%$ and $31.7 \%$ in invasive strains of E. coli and K. pneumoniae respectively (European Centre for Disease Prevention and Control 2018).

In France, the registration of temocillin follows a request from several professional organizations and associations (Haute Autorité de Santé 2015). The molecule has obtained a marketing authorization in December 2015 for the treatment of intra-abdominal and complicated urinary tract infections (UTI) due to ESBL-PE.

Temocillin breakpoints lack in EUCAST and CLSI guidelines for antibiotics susceptibility testing. Fuchs et al. first proposed to categorize as susceptible a strain displaying a MIC $\leq 16 \mathrm{mg} / \mathrm{L}$ and resistant if MIC $\geq 32 \mathrm{mg} / \mathrm{L}$ (Fuchs et al. 1985). The BSAC guidelines latter defined temocillin MIC breakpoints for Enterobacterales as susceptible if $\leq 8 \mathrm{mg} / \mathrm{L}$ for systemic infections and $\leq 32 \mathrm{mg} / \mathrm{L}$ for non-complicated UTI (British Society for antimicrobiol Chemotherapy 2013). In contrast, French guidelines proposed a unique breakpoint of $8 \mathrm{mg} / \mathrm{L}$ (CA-SFM 2020). In clinical laboratories, the routine assessment of temocillin susceptibility could be performed by discs diffusion methods, gradient strip test, or microdilution MIC. In comparison to microdilution or agar dilution, gradient strip tests appear a reliable method while major and very major error are more frequent using the discs diffusion method (Patel et al. 2013; Alexandre et al. 2018; Winckert et al. 2018).

We aim to assess the trend of temocillin resistance among invasive Enterobacterales strains isolated in France before and two years after the obtention of the marketing authorization. The GMC-11 project 
was carried out by the collaborative GMC study group, an association of 30 French clinical laboratories involved in clinical microbiology research.

\section{Methods}

\subsection{Clinical strains}

Seventeen French clinical laboratories spread over the country were enrolled in the study: 7 in the Paris area, 3 in the east, 4 in the north-west, 1 in the south-east, and 2 in the center of France (Table 1). Each center included 100 non-duplicate consecutive Enterobacterales strains (50 strains collected in 2014 and 50 strains collected in 2017) recovered from blood culture. The laboratories that did not keep the strains collected in 2014 were invited to include 100 strains collected in 2017. As temocillin is recommended for the treatment of Enterobacterales resistant to $3 G C$, each center has to include $60 \%$ of strains resistant to third-generation cephalosporins (3GC-R). Bacterial identification was performed using conventional biochemical methods (e.g. VITEK 2) or MALDI-TOF mass spectrometry as recommended by the manufacturers.

\subsection{Susceptibility testing}

The minimum inhibitory concentration (MIC) of temocillin was assessed by Etest (bioMérieux, Lyon, France) as recommended by the manufacturer. Nowadays, there are no consensual guidelines for temocillin susceptibility testing interpretation. Temocillin susceptibility was interpreted using breakpoints of $8 \mathrm{mg} / \mathrm{L}$ according to CA-SFM EUCAST and BCSA systemic breakpoints (British Society for antimicrobiol Chemotherapy 2013; Comité de l'antibiogramme de la Société Française de Microbiologie 2020), $16 \mathrm{mg} / \mathrm{L}$ as first suggested by Fuchs et al. (Fuchs et al. 1985), and $32 \mathrm{mg} / \mathrm{L}$ according to BSAC urinary breakpoints (British Society for antimicrobiol Chemotherapy 2013). The susceptibility to eight others routinely tested antibiotics including piperacillin-tazobactam, cefotaxime, pivmecillinam, nalidixic acid, ofloxacin, cotrimoxazole, amikacin, and ertapenem, was assessed by the disk diffusion method. For these antibiotics, susceptibility testing was assessed using EUCAST v7.1 guidelines (European Committee on Antimicrobial Susceptibility Testing 2019). A phenotypic-based 
approach was used to distinguish ESBL-PE and cephalosporinase-overproducing (COPE) strains as previously described (Comité de l'antibiogramme de la Société Française de Microbiologie 2020).

\subsection{Statistical analysis}

Statistical analysis was performed using IBM SPSS Statistics version 20.0.0 (IBM Corp., Armonk, NY, USA). Categorical and continuous variables were compared using the Chi-square and Student test, respectively. As the clinical strains were included according to their susceptibility to 3GC, all analyses were performed within 3GC-susceptible (3GC-S) and 3GC-resistant (3GC-R) strains. The rate of temocillin resistance among the three main species and overall strains was analyzed after grouping strains collected in 2014 and 2017.

\section{Results}

\subsection{Clinical strains}

A total of 1,387 strains were included ranging in 363 strains collected in 2014 and 1,024 strains collected in 2017 (Table 2). Eight laboratories included clinical strains collected both in 2014 and 2017 while the others included strains collected only in 2017. Enterobacterales species collected are listed in Table S1: E. coli accounted for $56.4 \%$, K. pneumoniae $15.3 \%$, E. cloacae complex $12.0 \%$, and other Enterobacterales species 16.3\%. The species distribution was not significantly different between 2014 and 2017 for E. coli and E. cloacae complex. However, a significantly higher proportion of $K$. pneumoniae $(10.5 \%$ vs $17.0 \%, P=0.003)$ were included in 2017 . 3GC-R strains proportion was significantly higher in 2014 than in 2017 (54.5\% vs 46.9\%, $P=0.012)$. Among 3GC-R strains, ESBL and cephalosporinase-overproduction mechanisms accounted for about two-thirds $(n=460)$ and one third ( $\mathrm{n}=198)$, respectively, with no significant difference between 2014 and $2017(P=0.22)$.

\subsection{Overall temocillin resistance}

At breakpoints of $8 \mathrm{mg} / \mathrm{L}, 16 \mathrm{mg} / \mathrm{L}$ and $32 \mathrm{mg} / \mathrm{L}$, the overall rate of temocillin resistance was under $5 \%$ $(4.6 \%, 0.4 \%$ and $0.0 \%$, respectively) for $3 G C-S$ strains. The rate of resistance was significantly higher 
$(P<0.001)$ for 3 GC-R strains, ranging from $2.2 \%$ at the breakpoint of $32 \mathrm{mg} / \mathrm{L}$ to $7.6 \%$ and $26.7 \%$ at the breakpoints of $16 \mathrm{mg} / \mathrm{L}$ and $8 \mathrm{mg} / \mathrm{L}$. At the breakpoint of $8 \mathrm{mg} / \mathrm{L}$, COPE displayed a significantly higher rate of temocillin resistance than ESBL-PE (36.0\% vs $21.1 \% ; P<0.001)$. Considering the breakpoint of $16 \mathrm{mg} / \mathrm{L}, 3.5 \%$ of ESBL-PE were resistant to temocillin versus $13 \%$ of COPE $(P<0.001)$.

$\mathrm{MIC}_{50}$ and $\mathrm{MIC}_{90}$ for $3 \mathrm{GC}-\mathrm{S}$ strains were $4 \mathrm{mg} / \mathrm{L}$ and $8 \mathrm{mg} / \mathrm{L}$, respectively. MIC distribution was higher for 3GC-R strains and much more for COPE strains. Overall, COPE displayed $\mathrm{MIC}_{50}$ and $\mathrm{MIC}_{90}$ of $8 \mathrm{mg} / \mathrm{L}$ and $24 \mathrm{mg} / \mathrm{L}$, respectively, while ESBL-PE $\mathrm{MIC}_{50}$ and $\mathrm{MIC}_{90}$ were $6 \mathrm{mg} / \mathrm{L}$ and $12 \mathrm{mg} / \mathrm{L}$ respectively. At the breakpoint of $32 \mathrm{mg} / \mathrm{L}$, almost all strains (3GC-S and 3GC-R) were susceptible to temocillin.

\subsection{Temocillin resistance by species}

At the breakpoint of $8 \mathrm{mg} / \mathrm{L}$, the rate of temocillin resistance was low among 3GC-S strains, ranging from $3.7 \%$ in E. coli to $4.9 \%$ in $K$. pneumoniae and $5.7 \%$ in E. cloacae complex ( $P=0.32)$ (Table 4). In contrast, among 3GC-R strains at the same breakpoint, E. cloacae complex displayed a significantly higher rate of resistance to temocillin $(40 \%)$ in comparison to K. pneumoniae $(24.0 \%)$, and E. coli (19.6\%) $(P=0.001)$. Among ESBL-PE, $18.6 \%, 24.6 \%$, and $27.1 \%$ of $E$. coli, K. pneumoniae, and E. cloacae complex were resistant to temocillin at the breakpoint of $8 \mathrm{mg} / \mathrm{L}$, respectively, while among COPE $27.0 \%$ and $48.0 \%$ of. E. coli and E. cloacae complex were resistant to temocillin respectively.

\subsection{Trend in temocillin resistance between 2014 and 2017}

The rates of temocillin resistance were not significantly different between 2014 and 2017 for both 3GC-S and 3GC-R strains except for ESBL-PE. Despite the small number of ESBL-PE included in 2014 (130 strains), strains collected in 2017 were significantly more resistant to temocillin than those included in $2014(23.9 \%$ vs $13.9 \% ; P=0.02)$ at the breakpoint of $8 \mathrm{mg} / \mathrm{L}$ (Table 3$)$. This finding was not noticed using higher breakpoints of 16 and $32 \mathrm{mg} / \mathrm{L}$. If considering solely the eight laboratories that include strains collected in 2014 and 2017, the same trend in increased resistance to temocillin was noticed for ESBL-PE at the breakpoint of $8 \mathrm{mg} / \mathrm{L}$. In contrast, temocillin resistance rate in COPE strains was similar in 2014 and 2017 (34.9\% vs 36.6\%, $P=0.8)$. 


\subsection{Associated resistance}

Associated resistances determined by the disc diffusion method were higher in 3GC-R strains than 3GC-S strains (Table 5). Regarding 3GC-S strains, temocillin was the most active antibiotic with amikacin, and ertapenem (Table S2) while mecillinam, amikacin, and ertapenem were more active than temocillin against 3GC-R strains. Among 3GC-S strains non-susceptible to at least one other antibiotic tested, resistance to temocillin ranged from $6.6 \%$ to $15.1 \%$ among cotrimoxazole, and mecillinam resistant strains respectively (Table 5). On the other hand, the rate of temocillin resistance in $3 G C-R$ isolates ranged from $22.1 \%$ to $48.6 \%$ in cotrimoxazole, and ertapenem resistant isolates respectively.

Temocillin remained active against $64.9 \%$ of $3 G C-R$ strains also resistant to piperacillin-tazobactam, ofloxacin and cotrimoxazole.

Of 1,270 strains tested for cefotaxime, piperacillin-tazobactam, and ertapenem, temocillin resistance was strongly correlated $(P<0.01)$ to the number of inactive beta-lactams. At the breakpoint of $8 \mathrm{mg} / \mathrm{L}$, the rate of temocillin resistance ranged from $3.7 \%$ (no resistance to other beta-lactams) to $60 \%$ (resistance to all three beta-lactams) (Table 6, Fig. 1).

\section{Discussion}

Temocillin remains highly active against Enterobacterales strains recovered from blood culture. It, therefore, represents a useful alternative to broad-spectrum antibiotics, such as carbapenem or piperacillin-tazobactam, to treat infections due to $3 G C-R$ strains. However, our results highlight 4 significant changes and trends: i) a higher rate of temocillin resistance among COPE than ESBL-PE; ii) the rate of temocillin resistance is correlated to the number of inactive beta-lactams; iii) a trend in increase resistance in ESBL-PE between 2014 and 2017; iv) two-third of the isolates resistant to 3GC, piperacillin/tazobactam, ofloxacin, and cotrimoxazole were susceptible to temocillin, confirming this molecule as a mainstay for the treatment of complicated UTI due to multi-drug resistant Enterobacterales. 
The mechanisms of resistance to temocillin in Enterobacterales are largely unknown. Interestingly, we found here that among 3GC-R strains, temocillin resistance was significantly higher in COPE than in ESBL-PE. To our knowledge, this finding has never been reported yet, probably because our study is based on a larger collection of strains than the previous reports. Moreover, these latter mainly focused on ESBL-PE. However, natural cephalosporinase-producer susceptible to $3 G C$ trend to display higher $\mathrm{MIC}_{90}$ than E. coli or natural penicillinase producer (Jules and Neu 1982; Livermore et al. 2006). In our work, this trend was significant for 3GC-R strains and especially for the species E. cloacae complex probably reflecting the existence of genetic determinants. Furthermore, the rate of temocillin resistance is strongly correlated to the number of inactive beta-lactams suggesting the accumulation of mechanisms of resistance to other beta-lactams might affect its susceptibility. It could be hypothesized that the high production of ESBL or AmpC might also hydrolyze temocillin at a low-level. Otherwise, it was suggested the resistance to temocillin could be due to a failure of the molecule entry via outer membranes porins (Verbist 1982). Indeed, the in vitro addition of EDTA allows a decrease of temocillin MICs for these strains (Jules and Neu 1982). As the modal distribution of MIC is close to the breakpoint of $8 \mathrm{mg} / \mathrm{L}$, a slight decrease of susceptibility would impact the temocillin susceptibility rate at this breakpoint (Verbist 1982; Rodriguez-Villalobos et al. 2006).

At the breakpoint of $8 \mathrm{mg} / \mathrm{L}$, the rate of 3CG-S strains resistant to temocillin was low and similar to previous studies including those published during the developing steps of the molecule (Verbist 1982; Yang and Livermore 1988). In contrast, $74.5 \%$ of the 3GC-R strains are resistant to temocillin. The rate of temocillin resistance among 3GC-R Enterobacterales was previously reported ranging from $63 \%$ to $94.9 \%$ (Livermore et al. 2006; Glupczynski et al. 2007; Tärnberg et al. 2011; Titelman et al. 2011; Duployez et al. 2016; Zykov et al. 2016; Ip et al. 2017; Mischnik et al. 2017; Alexandre et al. 2018; Kresken et al. 2018). These differences might be due to variability in epidemiology such as i) the rate of COPE and ESBL-PE among 3GC-R strains, ii) ESBL type as previously suggested (Livermore et al. 2006; Tärnberg et al. 2011), iii) the type of infection, E. coli strains collected from communityacquired UTI being less resistant to temocillin than those recovered from healthcare-associated infections (Alexandre et al. 2018).

The rate of temocillin resistance remained stable over the study period except for ESBL-PE for which a significant increase was noticed. It is noteworthy that we could rule out any bias regarding MICs achievement methodology between the two periods of study since all the laboratories used collections 
of frozen strains for the first period, and all MICs were assessed in 2017 using the same methodology. Two other facts might affect the rate of temocillin resistance in ESBL-PE. First, a significantly higher proportion of K. pneumoniae was included in 2017 than in 2014. But the same observation is made within K. pneumoniae strains. Then, a fewer number of laboratories included clinical strains collected in 2014 than in 2017. However, the same trend was also noticed for these laboratories. We can also hypothesize a change in ESBL enzyme type, but it is unlikely as it would have occurred at the same time and in all the centers located all over the country. It is possible the patients infected with ESBLPE were more frequently treated by antibiotics including temocillin which could explain this increase is only noticed for these strains.

In countries where temocillin is available and used for many years, the rate of temocillin resistance seems to be higher among ESBL-PE strains. Indeed, up to $37 \%$ and $33.8 \%$ of ESBL-PE strains recovered in United-Kingdom and Belgium during the 2000s were resistant to temocillin, respectively (Titelman et al. 2011; Mischnik et al. 2017). In Belgium, this rate is stable since the early 2000s (Vanhoof et al. 2001; Rodriguez-Villalobos et al. 2006; Livermore and Tulkens 2008). In France, Duployez et al. reported a rate of temocillin resistance of $28.7 \%$ among Enterobacterales strains collected in 3 hospitals located next to the Belgium border in 2015 (Duployez et al. 2019), which is higher than in the present study (13.9\%) but slightly less to that in Belgium (Rodriguez-Villalobos et al. 2006; Glupczynski et al. 2007). As no participant laboratories of the present study are located near the Belgium border, these differences could suggest a circulation of Enterobacterales strains across the French-Belgian border. The molecule was introduced in Belgium for clinical use in 1988 at the same time of the emergence of ESBL-PE, thus, no studies prior to this date including ESBL-PE were performed. Furthermore, in Hong-Kong, where the molecule is not available, the rate of temocillin resistance among ESBL-PE was assessed as $16.1 \%$ (Ip et al. 2017), which is similar to the rate recovered before the marketing authorization in France. The trend in increased resistance to temocillin among ESBL-PE needs to be confirmed by further epidemiological studies.

\section{Conclusion}

Temocillin represents a useful alternative to broad-spectrum antibiotics for the treatment of severe infections due to $3 G C-R$ strains. However, as a high proportion of these strains are resistant to 
temocillin, empiric treatment using temocillin should be avoided. To the best of our knowledge, this work is the first that include such a large collection of Enterobacterales species and strains in order to determine temocillin-resistant strains prevalence. Indeed, most of the previous studies focused only on E. coli and K. pneumoniae. This finding allowed us to notice a higher level of resistance among COPE and increasing resistance among ESBL-PE over time. Also, the resistance to temocillin is strongly correlated to the number of inactive other beta-lactams suggesting a multifactorial mechanism of resistance. Further epidemiological surveys are needed to assess trends in temocillin resistance among Enterobacterales.

\section{Acknowledgment}

Members of the GMC study group: Vincent Fihman, Jean-Winoc Decousser and Florian Piques (Department of microbiology, CHU H. Mondor, Créteil, France); Etienne Carbonnelle, Françoise Jaureguy, Alexandra Lomont and Jean-Ralph Zahar (Department of microbiology, CHU Avicenne, Bobigny, France); Hadrien Kimseng (Department of microbiology, Hôpital Paris Saint Joseph, Paris, France) ; Clémence Michon and Marie-Emmanuelle Juvin (Department of microbiology and hygiene, CHU de Nantes, Nantes, France); Bénédicte Langlois and Agathe Capitaine (Department of microbiology, CHU de Caen-Normandie, Caen, France); Céline Beauruelle (Department of microbiology, CHU de Brest, Brest, France); Anaëlle Muggeo and Anne Limelette (Department of microbiology, CHU de Reims, Reims, France), Tristan Diedrich (Department of microbiology, $\mathrm{CH}$ de Valencienne, Valenciennes, France); Anaïs Potron (Department of microbiology, CHRU de Besançon, Besançon, France ; National reference center for antibiotic Resistance in Pseudomonas sp. and Acinetobacter sp, CHRU de Besançon, Besançon, France ; UMR 6249 "Chrono-environment", University of Franche-Comté, Besançon, France), Lauranne Broutin (Department of microbiology, CHU de Poitiers, Poitiers, France); Amandine Henry (Department of clinical Biology, Hôpital A. Mignot, Le Chesnay, France); Gauthier Péan de Pontfilly (Department of microbiology, CHU Saint-Louis, Paris, France); Emilie Jolly, Marc Vasse, Amandine Henry, Marion Lecuru and Thomas Yung (Department of clinical biology, Hôpital Foch, Suresnes, France)

The authors gratefully thanks Eumedica pharmaceutical for providing temocillin Etest strips. 


\section{Funding}

None

\section{Competing interest}

The temocillin Etest strips (bioMérieux, Lyon, France) were provided without charge by Eumedica pharmaceutical.

\section{References}

Alexandre K, Réveillon-Istin M, Fabre R, Delbos V, Etienne M, Pestel-Caron M, et al. Temocillin against Enterobacteriaceae isolates from communityacquired urinary tract infections: Low rate of resistance and good accuracy of routine susceptibility testing methods. J Antimicrob Chemother. 2018;73(7):1848-53.

British Society for antimicrobiol Chemotherapy. BSAC Methods for Antimicrobial Susceptibility Testing, version 12 May 2013 [Internet]. Vol. 44, Bsac.Org.Uk. 2013. Available from: http://bsac.org.uk/wp-content/uploads/2012/02/Version-12-Apr-2013_final.pdf

CA-SFM. CASFM / EUCAST V1.1 Avril 2020 - Société Française de Microbiologie [Internet]. 2020 [cited 2020 Jun 21]. Available from: https://www.sfm-microbiologie.org/2020/04/07/casfm-eucastv1-0-avril-2020/

Comité de l'antibiogramme de la Société Française de Microbiologie. Recommandations 2020 V.1.1 Avril [Internet]. 2020. Available from: www.sfm-microbiologie.org

Duployez C, Loiez C, Cattoen C, Descamps D, Wallet F, Vachée A. In vitro susceptibility to mecillinam of Escherichia coli strains isolated from the urine of pregnant women. Med Mal Infect [Internet]. 2016 Dec 1 [cited 2020 Aug 24];46(8):436-41. Available from: https://pubmed.ncbi.nlm.nih.gov/27609597/

Duployez C, Loïez C, Cattoen C, Wallet F, Vachée A. In vitro activity of temocillin against extendedspectrum beta-lactamase-producing Escherichia coli and Klebsiella pneumoniae strains isolated from urinary tract infections in France. Med Mal Infect [Internet]. 2019 Feb 1 [cited 2020 Nov 9];49(1):47-53. Available from: https://pubmed.ncbi.nlm.nih.gov/30396720/

European Centre for Disease Prevention and Control. EARSS: Surveillance of antimicrobial resistance in Europe (2018) [Internet]. Surveillance of antimicrobial resistance in Europe. 2018. 
Available from: https://ecdc.europa.eu/en/publications-data/antimicrobial-resistance-surveillanceeurope-2016

European Committee on Antimicrobial Susceptibility Testing. Breakpoint tables for interpretation of

MICs and zone diameters Version 9.0 [Internet]. 2019. Available from: http://www.eucast.org.

Fuchs PC, Barry AL, Thornsberry C, Jones RN. Interpretive criteria for temocillin disk diffusion susceptibility testing. Eur J Clin Microbiol [Internet]. 1985 Feb [cited 2020 Nov 9];4(1):30-3. Available from: https://link.springer.com/article/10.1007/BF02148656

Glupczynski Y, Huang TD, Berhin C, Claeys G, Delmée M, Ide L, et al. In vitro activity of temocillin against prevalent extended-spectrum beta-lactamases producing Enterobacteriaceae from Belgian intensive care units. Eur J Clin Microbiol Infect Dis [Internet]. 2007 Nov [cited 2020 Nov 9];26(11):777-83. Available from: https://pubmed.ncbi.nlm.nih.gov/17668253/

Haute Autorité de Santé. Negaban. Avis de la commission de la transparence du 1er avril 2015

[Internet]. 2015. Available from: https://www.has-sante.fr/upload/docs/evamed/CT14132_NEGABAN_PIC_INS_Avis2_CT14132.pdf

Ip M, Lai CK, Fung KSC, Wong K-T, Zhu C, Van de Velde S, et al. Activity of temocillin and 15 other agents, including fosfomycin and colistin, against Enterobacteriaceae in Hong Kong. Eur $\mathrm{J}$ Clin Microbiol Infect Dis [Internet]. 2017 Dec 25;36(12):2491-4. Available from: http://link.springer.com/10.1007/s10096-017-3091-8

Jules K, Neu HC. Antibacterial activity and $\beta$-lactamase stability of temocillin. Antimicrob Agents Chemother [Internet]. 1982 [cited 2020 Nov 9];22(3):453-60. Available from: https://pubmed.ncbi.nlm.nih.gov/6982681/

Kresken M, Körber-Irrgang B, Pfeifer Y, Werner G. Activity of temocillin against CTX-M-producing Escherichia coli and Klebsiella pneumoniae from Germany [Internet]. Vol. 51, International Journal of Antimicrobial Agents. Elsevier B.V.; 2018 [cited 2020 Nov 9]. p. 159-60. Available from: https://pubmed.ncbi.nlm.nih.gov/28705669/

Labia R, Baron P, Masson JM, Hill G, Cole M. Affinity of temocillin for Escherichia coli K-12 penicillinbinding proteins. Antimicrob Agents Chemother. 1984;26(3):335-8.

Livermore DM, Hope R, Fagan EJ, Warner M, Woodford N, Potz N. Activity of temocillin against prevalent ESBL- and AmpC-producing Enterobacteriaceae from south-east England. $\mathrm{J}$ Antimicrob Chemother [Internet]. 2006 May 1 [cited 2019 Dec 14];57(5):1012-4. Available from: http://academic.oup.com/jac/article/57/5/1012/764409/Activity-of-temocillin-against-prevalent- 
ESBL-and

Livermore DM, Tulkens PM. Temocillin revived. J Antimicrob Chemother [Internet]. 2008 Nov 19 [cited 2019 Dec 14];63(2):243-5. Available from: https://academic.oup.com/jac/articlelookup/doi/10.1093/jac/dkn511

Mischnik A, Baumert P, Hamprecht A, Rohde A, Peter S, Feihl S, et al. Susceptibility to cephalosporin combinations and aztreonam/avibactam among third-generation cephalosporin-resistant Enterobacteriaceae recovered on hospital admission. Int J Antimicrob Agents. 2017;

Patel TA, Dilley R, Williams A, Vanstone GL, Balakrishnan I. Comparison of the Phoenix automated system, the Etest method and broth microdilution in determining temocillin susceptibility of Enterobacteriaceae. J Antimicrob Chemother. 2013;68(7):1685-6.

Rodriguez-Villalobos H, Malaviolle V, Frankard J, de Mendonça R, Nonhoff C, Struelens MJ. In vitro activity of temocillin against extended spectrum $\beta$-lactamase-producing Escherichia coli. $\mathrm{J}$ Antimicrob Chemother. 2006;57(4):771-4.

Tärnberg M, Östholm-Balkhed Å, Monstein HJ, Hällgren A, Hanberger H, Nilsson LE. In vitro activity of beta-lactam antibiotics against CTX-M-producing Escherichia coli. Eur J Clin Microbiol Infect Dis [Internet]. 2011 Aug [cited 2020 Nov 9];30(8):981-7. Available from: https://pubmed.ncbi.nlm.nih.gov/21298459/

Titelman E, Iversen A, Kahlmeter G, Giske CG. Antimicrobial susceptibility to parenteral and oral agents in a largely polyclonal collection of CTX-M-14 and CTX-M-15-producing Escherichia coli and Klebsiella pneumoniae. APMIS [Internet]. 2011 Dec [cited 2020 Nov 9];119(12):853-63. Available from: https://pubmed.ncbi.nlm.nih.gov/22085361/

Vanhoof R, Bérin C, Carpentier M, Fagnart O, Glupczynski Y, Mans I, et al. Comparative in vitro activity of temocillin and other antimicrobial agents against enterobacteriaceae isolated from patients admitted to five Belgian hospitals. Acta Clin Belg [Internet]. 2001 [cited 2020 Nov 9];56(6):354-9. Available from: https://pubmed.ncbi.nlm.nih.gov/11881320/

Verbist L. In vitro activity of temocillin (BRL 17421), a novel $\beta$-lactam antibiotic. Antimicrob Agents Chemother. 1982;22(4):535-40.

Winckert A, Descy J, Baghoud M, Van Banbeke F, Meex C, Melin P. Infections urinaires: la CMI de la témocilline est-elle fiable ? [Internet]. 2018. Available from: https://www.ricai.fr/archives-2018

Woodford N, Pike R, Meunier D, Loy R, Hill R, Hopkins KL. In vitro activity of temocillin against multidrug-resistant clinical isolates of Escherichia coli, Klebsiella spp. and Enterobacter spp., and 
evaluation of high-level temocillin resistance as a diagnostic marker for OXA-48 carbapenemase. J Antimicrob Chemother. 2014;69(2):564-7.

Yang Y, Livermore DM. Activity of temocillin and other penicillins against $\beta$-lactamase-inducible and stably derepressed enterobacteria. J Antimicrob Chemother [Internet]. 1988 Sep [cited 2020 Nov 9];22(3):299-306. Available from: https://pubmed.ncbi.nlm.nih.gov/3263354/

Zykov IN, Sundsfjord A, Småbrekke L, Samuelsen $\varnothing$. The antimicrobial activity of mecillinam, nitrofurantoin, temocillin and fosfomycin and comparative analysis of resistance patterns in a nationwide collection of ESBL-producing Escherichia coli in. Infect Dis [Internet]. 2016;48(2):99_ 107. Available from: http://www.tandfonline.com/action/journallnformation?journalCode=infd20 
Tables.

Table 1 Location of participating center in France

\begin{tabular}{llll}
\hline \multicolumn{1}{c}{ Hospital name } & \multicolumn{1}{c}{ Hospital Type } & \multicolumn{1}{c}{ City } & Location \\
\hline Hôpital Foch & PPE* $^{*}$ & Suresnes & \\
GH Paris - Saint-Joseph & PPE* $^{*}$ & Paris & \\
HIA Bégin & Military hospital & Saint Mandé & \\
CHU Avicenne & Teaching hospital & Bobigny & Paris area \\
CHU Henri Mondor & Teaching hospital & Créteil & \\
CHU Necker Enfants-malades & Teaching hospital & Paris & \\
Institut Curie & PPE* & Villejuif & \\
\hline CHU Caen Normandie & Teaching hospital & Caen & \\
CHU de Nantes & Teaching hospital & Nantes & North-west \\
CHU Pontchaillou & Teaching hospital & Rennes & \\
Hôpital Pasteur & General hospital & Dieppe & \\
\hline CHU de Nice & Teaching hospital & Nice & South-east \\
\hline CHU Jean Bernard & Teaching hospital & Poitiers & Center \\
CHU Bretonneau & Teaching hospital & Tours & \\
\hline CHU de Reims & Teaching hospital & Reims & East \\
Hôpital Civil de Strasbourg & Teaching hospital & Strasbourg & \\
CHU Jean Mimoz & Teaching hospital & Besançon & \\
\hline
\end{tabular}

* Private hospital with public engagement

Table 2 Characteristics of Enterobacteriales included in 2014 and 2017

\begin{tabular}{lccc} 
& $\mathbf{2 0 1 4}$ & $\mathbf{2 0 1 7}$ & $\boldsymbol{P}$ \\
\hline \multicolumn{1}{c}{ Total number of strains } & 363 & 1024 & $/$ \\
\hline Species distribution & & & \\
E. coli & $210(57.9 \%)$ & $572(55.9 \%)$ & 0.5 \\
E. cloacae complex & $43(11.8 \%)$ & $124(12.1 \%)$ & 0.9 \\
K. pneumoniae & $38(10.5 \%)$ & $174(17.0 \%)$ & $\mathbf{0 . 0 0 3}$ \\
Other species & $72(19.8 \%)$ & $154(15.0 \%)$ & $\mathbf{0 . 0 3}$ \\
\hline 3GC resistance & & & \\
3GC-S strains & $165(45.5 \%)$ & $544(53.1 \%)$ & \multirow{2}{*}{$\mathbf{0 . 0 1 2}$} \\
3GC-R strains & $198(54.5 \%)$ & $480(46.9 \%)$ & \\
COPE & $66(33.3 \%)$ & $134(28.0 \%)$ & \\
ESBL-PE & $130(65.7 \%)$ & $330(68.7 \%)$ & 0.22 \\
Other mechanisms & $2(1 \%)$ & $16(3.3 \%)$ & \\
\hline
\end{tabular}

Table 3 Temocillin susceptibility of Enterobacterales included in 2014 and 2017 


\begin{tabular}{lccccccccc}
\hline & \multicolumn{3}{c}{$8 \mathrm{mg} / \mathrm{L}$} & \multicolumn{3}{c}{$16 \mathrm{mg} / \mathrm{L}$} & \multicolumn{3}{c}{$32 \mathrm{mg} / \mathrm{L}$} \\
& 2014 & 2017 & $\mathrm{p}$ & 2014 & 2017 & $\mathrm{p}$ & 2014 & 2017 & $\mathrm{p}$ \\
\hline 3GC-S strains & $11(6.7 \%)$ & $21(3.9 \%)$ & 0.133 & $0(0.0 \%)$ & $3(0.6 \%)$ & $/$ & $0(0.0 \%)$ & $0(0.0 \%)$ & $/$ \\
3GC-R strains & $43(21.7 \%)$ & $138(28.8 \%)$ & 0.061 & $14(7.1 \%)$ & $38(7.7 \%)$ & $/$ & $3(1.5 \%)$ & $12(2.5 \%)$ & 0,6 \\
ESBL-PE & $18(13.9 \%)$ & $79(23.9 \%)$ & 0.02 & $3(2.3 \%)$ & $13(3.9 \%)$ & 0.6 & $0(0.0 \%)$ & $1(0.3 \%)$ & 1 \\
COPE & $23(34.9 \%)$ & $49(36.6 \%)$ & 0.8 & $9(13.6 \%)$ & $17(12.7 \%)$ & 0,8 & $1(1.5 \%)$ & $4(3.0 \%)$ & 1 \\
Other mechanisms & $2(100 \%)$ & $10(62.5 \%)$ & 0.53 & $2(100 \%)$ & $8(50 \%)$ & 0.6 & $2(100 \%)$ & $6(37.5 \%)$ & 1 \\
\hline
\end{tabular}

Table 4Temocillin susceptibility of 3GC-S and 3GC-R Enterobacterales strains collected in 2014 and 2017 at breakpoint of 8,16 , and $32 \mathrm{mg} / \mathrm{L}$.

\begin{tabular}{|c|c|c|c|c|c|c|}
\hline & \multirow{2}{*}{$\mathrm{Nb}$} & \multirow{2}{*}{$\mathrm{MIC}_{50}$} & \multirow{2}{*}{$\mathrm{MIC}_{90}$} & \multicolumn{3}{|c|}{$\%$ of resistant strains at breakpoint } \\
\hline & & & & $8 \mathrm{mg} / \mathrm{L}$ & $16 \mathrm{mg} / \mathrm{L}$ & $32 \mathrm{mg} / \mathrm{L}$ \\
\hline \multicolumn{7}{|l|}{ Overall species } \\
\hline $3 G C-S$ & 709 & 4 & 8 & 4.6 & 0.4 & 0.1 \\
\hline 3GC-R & 678 & 6 & 16 & 25.5 & 6.2 & 0.9 \\
\hline - COPE & 198 & 8 & 24 & 35.9 & 12.6 & 2.5 \\
\hline - ESBL-PE & 460 & 6 & 12 & 20.9 & 3.5 & 0.2 \\
\hline \multicolumn{7}{|l|}{ E. coli } \\
\hline 3GC-S & 459 & 4 & 6 & 3.7 & 0.2 & 0.0 \\
\hline 3GC-R & 316 & 6 & 12 & 19.6 & 3.2 & 0.6 \\
\hline - COPE & 37 & 6 & 16 & 27.0 & 8.1 & 2.7 \\
\hline - ESBL-PE & 279 & 6 & 12 & 18.6 & 2.6 & 0.4 \\
\hline \multicolumn{7}{|l|}{ K. pneumoniae } \\
\hline 3GC-S & 81 & 3 & 8 & 4.9 & 0.0 & 0.0 \\
\hline $3 G C-R$ & 129 & 4 & 16 & 24.0 & 3.9 & 0.0 \\
\hline - COPE & 11 & 1 & 1 & / & 1 & I \\
\hline - ESBL-PE & 118 & 1 & 16 & 24.6 & 3.4 & 0.0 \\
\hline \multicolumn{7}{|c|}{ E. cloacae complex } \\
\hline 3GC-S & 35 & 3 & 6 & 5.7 & 5.7 & 2.9 \\
\hline $3 G C-R$ & 125 & 8 & 24 & 40.0 & 12.8 & 0.8 \\
\hline - COPE & & 8 & 24 & 48.0 & 16.9 & 1.3 \\
\hline - ESBL-PE & 48 & 6 & 16 & 27.1 & 6.3 & 0.0 \\
\hline
\end{tabular}


Table 5 Rate of temocillin resistance among non-susceptible Enterobacterales to other antibiotics according to 3 CG susceptibility

\begin{tabular}{lcc}
\hline \multicolumn{1}{c}{ Non-susceptible antibiotics } & 3CG-R & 3CG-S \\
\hline Pivmecillinam & $26(32.5 \%)$ & $11(15.1 \%)$ \\
Piperacillin/tazobactam & $124(36.8 \%)$ & $6(9.8 \%)$ \\
Ertapenem & $17(48.6 \%)$ & $2(66.7 \%)$ \\
Nalidixic acid & $94(26.0 \%)$ & $12(10.5 \%)$ \\
Ofloxacin & $94(27.0 \%)$ & $12(13.9 \%)$ \\
Cotrimoxazole & $89(22.1 \%)$ & $9(6.6 \%)$ \\
Amikacin & $17(25.4 \%)$ & $2(18.2 \%)$ \\
Piperacillin/tazobactam + Ofloxacin + & $49(35.1 \%)$ & $2(20 \%)$ \\
Cotrimoxazole & $6(33.3 \%)$ & $1(20 \%)$ \\
Piperacillin/tazobactam + Ofloxacin + & $10(32.3 \%)$ & $2(20 \%)$ \\
Cotrimoxazole + Pivmecillinam & \\
Ofloxacin + Cotrimoxazol + Pivmecillinam & 10 \\
\hline
\end{tabular}

Table 6 Correlation between temocillin-resistant Enterobacterales and inactive beta-lactams (cefotaxime, piperacillin-tazobactam, ertapenem)

\begin{tabular}{|c|c|c|c|c|}
\hline \multirow{2}{*}{$\begin{array}{c}\text { Number of } \\
\text { inactive beta- } \\
\text { lactam }\end{array}$} & \multirow{2}{*}{$\begin{array}{l}\text { Total number of } \\
\text { strains }\end{array}$} & \multicolumn{3}{|c|}{$\begin{array}{l}\text { Number (\%) of strains non-susceptible } \\
\text { to temocillin according to breakpoint }\end{array}$} \\
\hline & & $8 \mathrm{mg} / \mathrm{L}$ & $16 \mathrm{mg} / \mathrm{L}$ & $32 \mathrm{mg} / \mathrm{L}$ \\
\hline 0 & 596 & $22(3.7 \%)$ & $1(0.2 \%)$ & $0(0.0 \%)$ \\
\hline 1 & 362 & $50(13.8 \%)$ & $5(1.4 \%)$ & $1(0.3 \%)$ \\
\hline 2 & 272 & $100(36.8 \%)$ & $29(10.7 \%)$ & $6(2.2 \%)$ \\
\hline$\geq 3$ & 40 & $24(60.0 \%)$ & $16(40.0 \%)$ & $8(20.0 \%)$ \\
\hline
\end{tabular}




\section{Figures.}

Fig. 1 Correlation between temocillin-resistant Enterobacterales and inactive beta-lactams (cefotaxime, piperacillin-tazobactam, ertapenem)

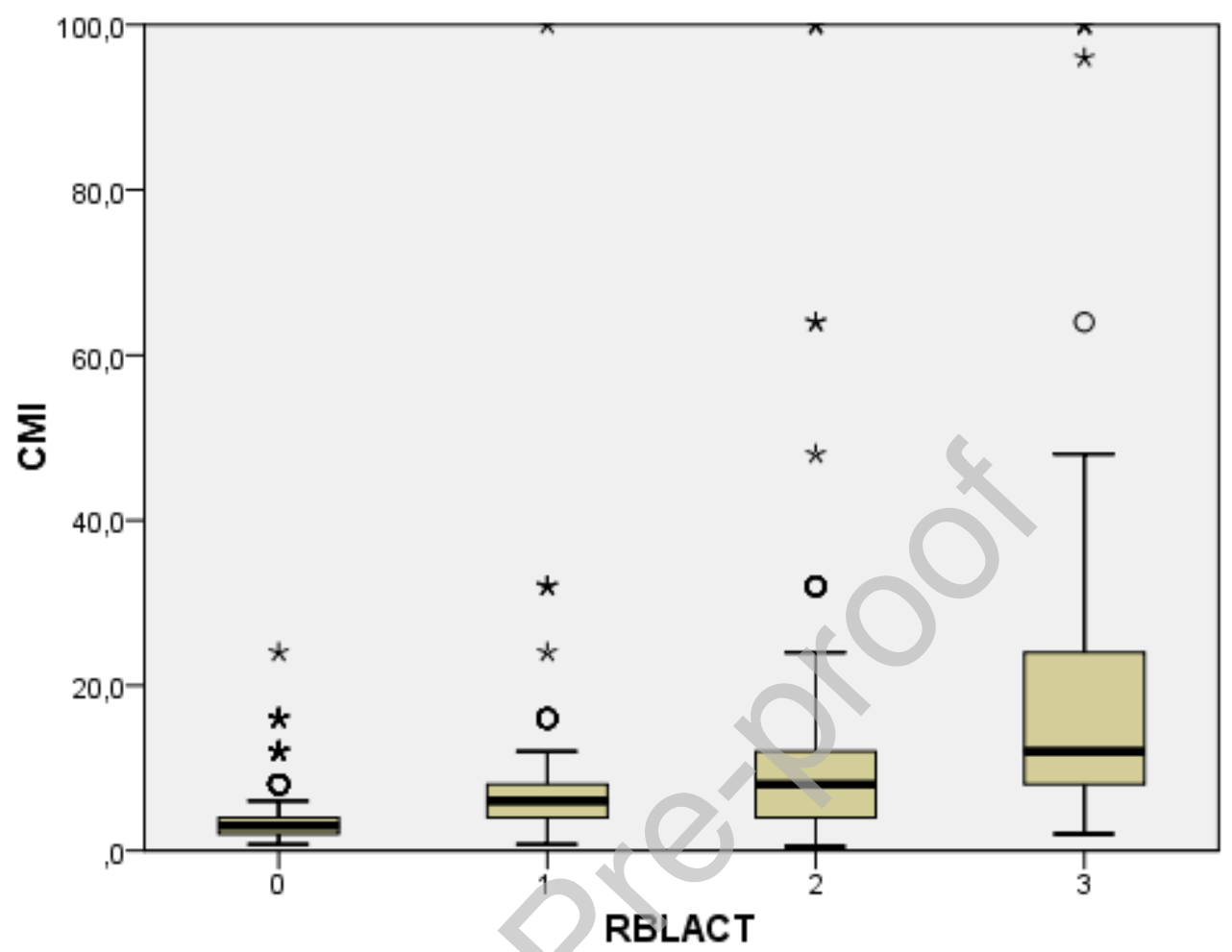

